\title{
Patient-Centered Care is Associated with Decreased Health Care Utilization
}

\author{
Klea D. Bertakis, MD, MPH, and Rabman Azari, PhD
}

Purpose: This article uses an interactional analysis instrument to characterize patient-centered care in the primary care setting and to examine its relationship with health care utilization.

Methods: Five hundred nine new adult patients were randomized to care by family physicians and general internists. An adaption of the Davis Observation Code was used to measure a patient-centered practice style. The main outcome measures were their use of medical services and related charges monitored over 1 year.

Results: Controlling for patient sex, age, education, income, self-reported health status, and health risk behaviors (obesity, alcohol abuse, and smoking), a higher average amount of patient-centered care recorded in visits throughout the 1-year study period was related to a significantly decreased annual number of visits for specialty care $(P=.0209)$, less frequent hospitalizations $(P=.0033)$, and fewer laboratory and diagnostic tests $(P=.0027)$. Total medical charges for the 1 -year study were also significantly reduced $(P=$ $.0002)$, as were charges for specialty care clinic visits $(P=.0005)$, for all patients who had a greater average amount of patient-centered visits during that same time period. For female patients, the regression equation predicted $15.47 \%$ of the variation in total annual medical charges compared with male patients, for whom 31.18\% of the variation was explained by the average percent of patient-centered care, controlling for sociodemographic variables, health status, and health risk behaviors.

Conclusions: Patient-centered care was associated with decreased utilization of health care services and lower total annual charges. Reduced annual medical care charges may be an important outcome of medical visits that are patient-centered. (J Am Board Fam Med 2011;24:229-239.)

Keywords: Charges and Fees, Patient-Centered Care, Utilization

Over the years, an extensive body of literature has described and advocated for a patient-centered approach to medical care. ${ }^{1-12}$ In its 2001 report, "Crossing the Quality Chasm: A New Health System for the 21st Century," ${ }^{5}$ the Institute of Medicine presented an action plan for reinventing the

This article was externally peer reviewed.

Submitted 20 July 2010; revised 7 December 2010; accepted 13 December 2010.

From the Department of Family and Community Medicine (KDB) and the Department of Statistics (RA), Center for Healthcare Policy and Research, University of California, Davis, Sacramento.

Funding: This project was supported by a grant (R18 HS06167) from the Agency for Healthcare Policy and Research, now known as the Agency for Healthcare Research and Quality.

Conflict of interest: none declared.

Corresponding author: Klea D. Bertakis, MD, MPH, Department of Family and Community Medicine, Center for Healthcare Policy and Research, University of California, Davis, 4860 "Y" Street, Suite 2300, Sacramento, CA 95817 (E-mail:kdbertakis@ucdavis.edu). health system to improve our nation's health. One of the 6 key components in achieving quality health care was identified as "patient-centeredness." Though there is no uniform definition of patientcentered communication, several scales have been developed to measure it. ${ }^{6}$ It would seem that patient-centered care is a multifaceted construct, and instruments designed to measure it have varying levels of reliability and relatively low concurrent validity. Nonetheless, these instruments generally measure the following communication behaviors: eliciting understanding and validating the patient's perspective; understanding the patient within his or her psychosocial context; reaching a shared understanding with the patient of the problem and its treatment; and creating a partnership in which "activated" patients share in decision making, power, and responsibility. ${ }^{4}$

Health care organizations are being challenged to provide quality medical care while managing 
costs. A patient-centered approach is increasingly being considered a paradigm for high-quality interpersonal care. There is still a lack of consistent research evidence linking patient-centered care to improved patient outcomes, ${ }^{8,13-17}$ but it has been demonstrated that a practice style emphasizing patient activation is associated with significantly lower primary care charges. ${ }^{18}$ Moreover, there is emerging evidence for an association between patient-centered communication and the utilization of medical resources. It has been found that patients who perceived their visit as having been patient-centered received fewer diagnostic tests and referrals. ${ }^{14}$ Others have reported that physicians who have visits characterized by the greatest amount of patient-centered communication also have the lowest expenses for diagnostic testing. ${ }^{19}$ In a recent study examining the determinants and outcomes of patient-centered care using an established interactional analysis instrument modified to characterize a patient-centered physician practice style, evidence was found to suggest that a patient-centered approach to primary care was associated with lower annual medical charges. ${ }^{20}$

A possible explanation for the relationship between patient-centered care and decreased health care utilization may be that patients experience decreased anxiety and increased trust in their physicians when they actively participate in their own care and feel that their physicians understand their symptoms. ${ }^{14,21}$ Physicians, in turn, may gain more information about the patient's concerns and questions while engaging in patient-centered communication. ${ }^{22}$ These patient and physician factors may all contribute to a decreased need for further diagnostics and consultations.

The object of the present study was to determine the amount of patient-centered care given to patients in a primary care setting over the course of 1 year and to relate this to the utilization of medical services and subsequent charges in 5 categories: (1) primary care clinic visits, (2) specialty care clinic visits, (3) emergency department visits, (4) hospitalizations, and (5) diagnostic services (laboratory, diagnostic, and radiologic tests). We sought to contribute to the findings of other studies investigating the relationship between patient-centered communications and medical costs by controlling for patient health status and health risk behaviors, in addition to sociodemographic characteristics, because these have been shown to significantly impact health resource use $e^{23,24}$ and the process of care..$^{25,26}$ By studying new patients (rather than a mix of new and established patients), statistically adjusting for health status and health risk behaviors and employing measures used in health services research, we attempted to diminish potential sources of bias and confounding to help clarify the association between a patient-centered approach and the use of health care resources.

Patient sex also impacts the doctor-patient interaction, ${ }^{27}$ as has been demonstrated in a number of studies. Female patients ask more questions, get more information, receive more counseling and preventive services, and have more participatory visits than male patients. ${ }^{28-30}$ These may be considered elements of patient-centered care. One recent study's findings suggested that, compared with male patients, women have interactions characterized by greater patient-centered communication. ${ }^{31}$ Moreover, women have higher medical care service utilization and higher associated charges than men. ${ }^{32}$ In consideration of these effects, patient sex was controlled in the analyses, and female and male patients were also analyzed separately in an effort to further explore the association between patientcentered care and medical charges.

Based on the literature and our own preliminary findings, we hypothesized that patient-centered medical care would be associated with decreased utilization of health care resources and subsequent charges.

\section{Methods \\ Subjects}

This was part of a larger study examining physician practice styles and associated patient outcomes. Study subjects consisted of new patients requesting outpatient appointments at a university medical center. Of the first 956 nonpregnant adults without a preference for a specific physician or specialty, $821(85 \%)$ agreed to participate. These patients were subsequently randomly assigned for primary care in either the family practice clinic or the general medicine clinic. This assignment method gave each patient an equal chance of being seen by providers in family medicine and internal medicine clinics, which is important because these 2 disciplines have demonstrated differences in practice style. ${ }^{33}$ Three hundred twelve (38\%) of these patients were excluded from the study because they 
did not keep their appointment or could not be included for scheduling reasons. A total of 509 patients participated in the study, providing informed consent in accordance with protocols approved by our institutional human subjects review committee. Medical care was provided by 26 family practice and 79 general internal medicine secondand third-year residents. Those 105 primary care physicians each saw an average of 4.8 patients (SD, 4.6 patients).

\section{Study Design}

Before the initial visit with their primary care provider, study patients were interviewed providing the following data: sociodemographic information, self-reported health status using the Medical Outcomes Study Short Form-36, screening for alcoholism using Michigan Alcohol Screening Test (MAST), and history of tobacco use. Height and weight measurements were also performed to calculate the patient's body mass index (BMI). Physicians were not given patient data from the interview before the visit to avoid influencing their behavior. The entire medical visit was videotaped in examination rooms equipped with wall-mounted, unobtrusive video cameras. Subsequent patient visits to their primary care providers were videotaped throughout the course of the 1-year study period.

\section{Independent Variable Measures}

The patient-centered care practice style was determined by analyzing the videotapes using a modified version of the Davis Observation Code (DOC), which is seen in Table $1 .^{34}$ The DOC is a reliable and valid interactional analysis system that has been used previously to detect physician practice style

Table 1. Individual Davis Observation Codes and Clusters

\begin{tabular}{|c|c|}
\hline Codes in Each Cluster & Abbreviated Definitions of Codes \\
\hline \multicolumn{2}{|l|}{ Technical cluster } \\
\hline Structuring interaction & Discussing what is to be accomplished in current interactions \\
\hline History taking & $\begin{array}{l}\text { Physician inquiring about or patient describing details related to the current complaint or to } \\
\text { prior illnesses }\end{array}$ \\
\hline Family information & Discussing family, medical, or social history and/or current family functioning \\
\hline Physical examination & Any aspect of physical examination of patient \\
\hline Evaluation feedback & Physician telling patient about results of history, physical, laboratory work, etc. \\
\hline Planning treatment & Physician prescribing a medication, diagnostic, or treatment plan \\
\hline Treatment effects & $\begin{array}{l}\text { Physician inquiring about or patient describing result of ongoing therapeutic } \\
\text { intervention }\end{array}$ \\
\hline Procedure & Any treatment or diagnostic procedure done in office \\
\hline \multicolumn{2}{|l|}{ Health behavior cluster } \\
\hline Compliance & Discussing previously requested behavior \\
\hline Health education & Physician presenting information to patient regarding health \\
\hline Health promotion & Physician asking for change in patient's behavior to increase or promote health \\
\hline Nutrition & Any question about or discussion about nutrition \\
\hline Exercise & Any question about or discussion about exercise \\
\hline \multicolumn{2}{|l|}{ Addiction cluster } \\
\hline Substance use & Any question about or discussion of drinking alcohol or use of other substances \\
\hline Smoking behavior & Any question about or discussion of smoking or use of tobacco \\
\hline \multicolumn{2}{|l|}{ Patient activation cluster } \\
\hline Health knowledge & $\begin{array}{l}\text { Physician asking or patient spontaneously offering what patient knows or believes } \\
\text { about health and disease }\end{array}$ \\
\hline Patient question & Patient asking question \\
\hline Chatting & Discussing topics not related to current visit \\
\hline \multicolumn{2}{|l|}{ Preventive service cluster } \\
\hline Preventive service & Physician discussing, planning, or performing any screening task for disease prevention \\
\hline \multicolumn{2}{|l|}{ Counseling Cluster } \\
\hline Counseling & $\begin{array}{l}\text { Physician discussing interpersonal relations or current emotional state of patient or } \\
\text { patient's family }\end{array}$ \\
\hline
\end{tabular}

Those Davis Observation Codes in bold print are included in the modified version of DOC, which measures Patient-Centered Care. 
differences in a variety of studies. ${ }^{23,35-39}$ Observers record the occurrence of each of 20 clinically significant behaviors during successive 15 -second observation intervals of the medical visit. For each code, the number of intervals during which the associated behavior is observed; then it is expressed as a percentage of the total of all DOC behaviors noted during the visit and can be interpreted as the relative emphasis of these behaviors during the course of the visit. Six different clusters of physician practice behaviors have been identified to characterize practice style based on an evaluation of the clinical and statistical relationships among the 20 DOC codes. The 6 practice behavior clusters include from 1 to 8 DOC behaviors: technical, health behavior, addiction, patient activation, preventive services, and counseling.

Based on the patient-centered care literature, we developed a modified DOC patient-centered care interactional analysis system (highlighted in Table 1). Mead and Bower ${ }^{6}$ have suggested that a patientcentered approach is a multifaceted construct that differs from the traditional biomedical approach in 5 important dimensions, each of which focuses on a key aspect of the doctor-patient interaction: (1) understanding the patient's illness within a broader biopsychosocial context; (2) appreciating the patient's experience of illness; (3) advocating for an egalitarian relationship; (4) creating a therapeutic alliance; and (5) acknowledging the impact of the participants' personal qualities on the medical encounter. We incorporated these key dimensions of patient-centered care when identifying the specific DOC items included in the instrument measuring patient-centered care. ${ }^{20}$ Because creating an egalitarian relationship and therapeutic alliance are such important elements of patient-centered care, we initially selected the DOC behaviors included in the patient activation cluster ("health knowledge," "patient question," and "chatting"). It should be noted that "chatting" also identifies a portion of the influence of the physician's and patient's personalities on the interaction. "Counseling" was also included to capture the psychosocial issues impacting the patient. The "treatment effects" code seeks to measure how the illness and its treatment are affecting the patient. This differs from the "compliance" item, in which the emphasis is on whether the patient has adhered to what the physician has previously instructed him/her to do. The items regarding "nutrition" and "exercise" focus on pa- tient lifestyle and are more of a give and take of information between doctor and patient, as opposed to "health promotion," in which the physician asks for a specific change in the patient's behavior. It is important to note that DOC is not a comprehensive instrument for capturing all elements of physician-patient interaction (such as a transcribing all utterances). Rather, it has been used to identify clinically relevant behaviors, and the codes selected for use in the modified instrument reflect this.

For each of the 8 individual codes mentioned above, the number of intervals during which the behavior was observed and expressed is a percentage of the total number of DOC behaviors. To determine the presence of any observer bias, approximately $20 \%$ of the videotapes were coded by a second observer, with a stratified $\kappa$ coefficient of agreement of $91.6 \%{ }^{40}$

The Medical Outcomes Study Short Form-36 is a reliable and valid 36-item questionnaire made up of 8 scales: (1) general health, (2) physical function, (3) physical role, (4) mental role, (5) social function, (6) pain, (7) energy, and (8) mental health. Higher scores reflect better health status, and chronic medical conditions, such as diabetes, hypertension, coronary heart disease, arthritis, and lung problems, have a unique negative effect on scores. ${ }^{41,42}$ Summary measures describe a physical component score and a mental component score. ${ }^{43,44}$

The BMI is the recommended method for measuring obesity in clinical settings according to the National Institutes of Health guidelines. BMI is calculated as weight $(\mathrm{kg})$ divided by the square of height $\left(\mathrm{m}^{2}\right)$. Patients with a BMI of 18.5 to 24.9 are considered "normal"; those with BMI of 25 to 29.9 are "overweight"; and those having a BMI $\geq 30$ are "obese." 45

The short version of the MAST was used to detect alcoholism. ${ }^{46,47}$ This "brief MAST" consists of a 10-question subset of the original 25-item MAST and has been demonstrated to be a reliable screening instrument in both clinical and nonclinical settings. ${ }^{48}$ All study patients who stated they had ever had an alcoholic drink were asked the 10 questions from the brief MAST.

Each study participant was questioned about his/ her tobacco use/smoking history. Patients were designated "nonsmokers" if they had never smoked or had not smoked tobacco for 15 years or longer. The decision to include previous smokers who had 
not smoked for 15 years with nonsmokers was based on a recent report by the surgeon general on the health consequences of smoking and the benefits of quitting. ${ }^{49}$ After 10 to 15 years, a previous tobacco user's risk of premature death approaches that of a person who has never smoked.

\section{Dependent Variables}

Medical center resource use for 1 year of care was determined through a review of each patient's comprehensive medical record. The numbers of primary care clinic visits, specialty care clinic visits, emergency department visits, hospitalizations, and laboratory, diagnostic, and radiologic tests (diagnostic services) were counted. Medical charges for all these services were obtained from the centralized institutional billing unit. Charges, used as a proxy for medical costs, were assigned to 1 of 5 categories: (1) primary care clinics, (2) specialty care clinics, (3) emergency departments, (4) hospitalizations (including outpatient surgery admissions), and (5) diagnostic services. In addition, a year-long total for these 5 charge categories was calculated for each patient. Patients were also provided with prepaid postcards on a quarterly basis to report medical care obtained elsewhere. We received some responses that indicated negligible out-of-system use, but the exact amount of such utilizations was impossible to evaluate. Therefore, we limited our analyses to charges occurring within the system.

\section{Statistical Analysis}

Generalized linear models were used to model the number of primary care, specialty care, and emergency department visits; hospitalizations; and diagnostic services, as well as medical charges, as functions of the patients' sociodemographic characteristics, health status (both mental component score and physical component score), obesity, smoking, alcohol abuse, and patient-centered care (averaged over 1 year). The statistical modeling was done in 3 different steps. First, negative binomial regressions were fit to the number of utilizations of health care services to account for skewness and overdispersion of the data. Then, a 2-phase regression was used to model the utilization of and charges for specialty and emergency department visits, hospitalizations, and diagnostic services. In the first phase, logistic regressions were used to estimate the probability of utilization of medical services. In the second phase, linear regressions were fit on log-transformed medical charges for patients who utilized these services. Finally, linear regressions were fit to log-transformed total charges for all 509 patients and male and female patients separately. The sociodemographic characteristics were used as control variables in the models and were not removed, even if they did not attain statistical significance.

\section{Results}

During the 1-year study period, the median percentage of patient-centered care during the primary care visits was $14.90 \%$ (range, $2.10 \%$ to $36.15 \%)$. Table 2 shows sociodemographic and health data for all 509 patients, as well as the study population divided into 2 groups: (1) those who received patient-centered care below the yearlong median ( $\mathrm{n}=254)$; and (2) those who received more than or equal to the median patient-centered care $(\mathrm{n}=255)$.

Descriptive results of the dependent variablesboth utilization of medical resources and associated charges-are presented in Table 3. Once again, study patients were split into 2 groups based on the percentage of patient-centered care received during the study period. It is interesting to note that the total annual charges for patients who had less patient-centered care had median total charges of $\$ 1435.00$, compared with $\$ 948.00$ (51.37\% more) for those patients whose health care was characterized as more patient centered $(P=.0058)$.

As stated previously, generalized linear models were used to investigate the association between patient-centered care and utilization for medical services during the 1-year study period while controlling for the other variables that previously have been found to impact medical encounters and utilization, such as patient sex, age, education, income, self-reported health status, and health risk behaviors (obesity, alcohol abuse, and smoking).

We explored the relationship of patient-centered care and the number of times that each of the 5 categories of health care services (primary care clinic visits, specialty care clinic visits, emergency department visits, hospitalizations, and diagnostic services) was utilized by all patients during 1 year of care. The negative binomial regression with $\log$ link was used in modeling the relationship. A greater average percentage of patient-centered care during the 1-year study period was significantly 
Table 2. Sociodemographic and Health Data for All Study Patients $(n=509)$ and Patients with Yearling Patient-Centered Care Below $(n=254)$ and Greater than or Equal to $(n=255)$ the Median

\begin{tabular}{|c|c|c|c|}
\hline & All Patients $(\mathrm{n}=509)$ & $<$ Median $(\mathrm{n}=254)$ & $\geq$ Median $(\mathrm{n}=255)$ \\
\hline \multicolumn{4}{|l|}{ Sex $(\%)$} \\
\hline Male & 38.11 & 39.37 & 36.86 \\
\hline Female & 61.89 & 60.63 & 61.14 \\
\hline Age (mean years [SD]) & $41.74(14.73)$ & $42.24(14.30)$ & $41.24(15.15)$ \\
\hline Education (mean years [SD]) & $12.61(2.73)$ & $12.32(2.59)$ & $12.89(2.85)$ \\
\hline \multicolumn{4}{|l|}{ Income* $(\%)$} \\
\hline$<\$ 10,000$ & 49.11 & 55.56 & 42.69 \\
\hline$\$ 10,000-\$ 19,999$ & 24.75 & 24.60 & 24.90 \\
\hline$\$ 20,000-\$ 29,999$ & 10.50 & 10.32 & 10.67 \\
\hline$\$ 30,000-\$ 39,999$ & 6.14 & 2.38 & 9.88 \\
\hline$\$ 40,000-\$ 49,999$ & 4.16 & 3.97 & 4.35 \\
\hline$\geq \$ 50,000$ & 5.35 & 3.17 & 7.51 \\
\hline Physical health status $^{\dagger}$ (n [mean]) & $40.44(11.88)$ & $39.01(12.07)$ & $41.87(11.53)$ \\
\hline Mental health status ${ }^{\dagger}$ (n [mean]) & $43.99(12.55)$ & $43.92(12.36)$ & $44.05(12.76)$ \\
\hline $\mathrm{BMI}($ mean) & $29.76(8.39)$ & $29.19(7.85)$ & $30.33(8.87)$ \\
\hline Alcohol abuse (\%) & 7.69 & 9.84 & 5.53 \\
\hline Smoker (\%) & 67.85 & 74.41 & 61.26 \\
\hline
\end{tabular}

*Income data was available for 505 study patients.

${ }^{\dagger}$ Physical health status and mental health status were measured by the physical and mental components of the Medical Outcomes Study Short Form-36. The established means for these are 50 (SD, 10). BMI, body mass index.

related to fewer specialty care clinic visits $(P=$ $.0209)$; fewer hospitalizations $(P=.0033)$; and fewer laboratory and diagnostic tests ordered $(P=$ $.0027)$.

We then used a 2-phase regressions to model utilization of and charges for specialty and emergency department visits, hospitalizations, and diagnostic services. First, logistic regressions were used to predict the probability of using these services. Then, linear regressions were fit to log-transformed charges for these services. The patientcenteredness score was only significant in determining the utilization of and charges for specialty care The results, shown in Table 4 , indicate that higher average patient-centered care reduces the odds of using specialty clinics $(P=.0417)$. Con-

Table 3. Descriptive Statistics for Medical Resource Use and Charges $(n=509)$

\begin{tabular}{|c|c|c|c|c|}
\hline & \multicolumn{2}{|c|}{ Below Median Patient-Centered Care $(\mathrm{n}=254)$} & \multicolumn{2}{|c|}{$\begin{array}{l}\text { Equal or Above Median Patient-Centered } \\
\text { Care }(\mathrm{n}=255)\end{array}$} \\
\hline & Mean (SD) & Median (Range) & Mean (SD) & Median (Range) \\
\hline \multicolumn{5}{|l|}{ Type of visits } \\
\hline Primary care & $3.64(2.94)$ & $3.00(1-24.00)$ & $3.66(3.38)$ & $3.00(1-24.00)$ \\
\hline Specialty care & $2.94(4.50)$ & $1.00(0-26.00)$ & $2.22(4.06)$ & $0.00(0-21.00)$ \\
\hline Emergency department & $0.35(0.98)$ & $0.00(0-8.00)$ & $0.22(0.65)$ & $0.00(0-4.00)$ \\
\hline Hospitalizations & $0.25(0.75)$ & $0.00(0-6.00)$ & $0.11(0.42)$ & $0.00(0-3.00)$ \\
\hline Diagnostic services & $10.42(11.86)$ & $7.00(0-90.00)$ & $7.42(9.63)$ & $5.00(0-89.00)$ \\
\hline \multicolumn{5}{|l|}{ Type of charges $(\$)$} \\
\hline Primary care & $338.18(267.00)$ & $274.00(0-1,893.10)$ & $322.34(312.37)$ & $222.50(0-2,017.00)$ \\
\hline Specialty care & $646.37(1,758.88)$ & $128.00(0-16,528.10)$ & $329.41(746.67)$ & $0.00(0-6,168.00)$ \\
\hline Emergency department & $550.93(1,913.96)$ & $0.00(0-18,782.50)$ & $256.35(846.09)$ & $0.00(0-6,596.50)$ \\
\hline Hospitalizations & $5,360.35(22,566.23)$ & $0.00(0-194,958.50)$ & $2,547.00(11,266.65)$ & $0.00(0-123,446.00)$ \\
\hline Diagnostic services & $1,413.30(2,311.54)$ & $532.00(0-23,190.50)$ & $886.30(1,368.26)$ & $390.50(0-10,645.50)$ \\
\hline Total charges & $8,308.32(24,811.19)$ & $1,435.00(49.5-203,234.50)$ & $4,341.40(12,575.57)$ & $948.00(0-134,788.50)$ \\
\hline
\end{tabular}


Table 4. Two-Part Regression Models for Utilization of Specialty Care Clinic and Charges Using Patient-Centeredness, Sex, Age, Education, Income, Obesity, Smoking, Alcohol Abuse, Mental and Physical Health Status as Explanatory Variables

\begin{tabular}{|c|c|c|c|c|c|c|}
\hline \multirow[b]{2}{*}{ Dependent Variable } & \multirow[b]{2}{*}{ Independent Variable* } & \multicolumn{2}{|l|}{ Utilization $^{\dagger}$} & \multicolumn{3}{|c|}{ Charges $^{\ddagger}$} \\
\hline & & Odds Ratio (95\% CI) & $P$ & SE & $P$ & $\mathrm{R}^{2}$ \\
\hline \multirow{10}{*}{$\begin{array}{l}\text { Specialty Care Clinic } \\
\quad(\mathrm{n}=260)\end{array}$} & Female sex & $1.636(1.083-2.471)$ & .0192 & -0.0127 & .8427 & 0.1086 \\
\hline & Age & $1.026(1.012-1.040)$ & .0003 & 0.1168 & .0653 & \\
\hline & Education & $1.005(0.933-1.082)$ & .8972 & -0.0052 & .9348 & \\
\hline & Income & $1.020(0.947-1.099)$ & .5944 & 0.0223 & .7376 & \\
\hline & Obesity & $1.705(1.157-2.514)$ & .0070 & -0.0360 & .5592 & \\
\hline & Smoking & $1.153(0.756-1.757)$ & .5088 & 0.0187 & .7684 & \\
\hline & Alcohol abuse & $2.210(1.041-4.692)$ & .0391 & -0.0533 & .3932 & \\
\hline & Mental health status & $1.010(0.994-1.026)$ & .2285 & 0.0810 & .1962 & \\
\hline & Physical health status & $0.979(0.963-0.996)$ & .0154 & -0.1423 & .0266 & \\
\hline & Patient-centered care & $0.966(0.934-0.999)$ & .0417 & -0.2239 & .0005 & \\
\hline
\end{tabular}

*All independent variables are baseline measurements except for the patient centered care, which is averaged over 1 year of care.

${ }^{\dagger}$ Utilization results were obtained by logistic regression models.

${ }^{\ddagger}$ Medical charges for specialty care are in log-transformed dollars, with mean 6.04 (SD, 1.24).

SE, standardized error.

trolling for all the other variables in the model, if the patient-centered care increases by $1 \%$, the odds of using a specialty clinic will be reduced by about $3 \%$. Table 4 also shows that higher patient-centered care results in reduced specialty charges $(P=$ $.0005)$.

In Table 5, we see that the greater average amount of patient-centered care received during the course of the year was significantly associated with lower total charges for health care during the same time period $(P=.0002)$. As expected, female sex $(P=.0115)$, advanced age $(P<.0001)$, and lower physical health status $(P<.0001)$ were also significantly related to higher total medical charges. This model explained $21.42 \%$ of the variation in total annual medical charges.

The effect of sex was further explored; regression equations for female and male patients were analyzed separately, and total medical charges were explained by the average percentage of patient-

Table 5. Standardized Estimates from Regression Equations in Which Total Medical Charges* are Explained by the Average Percentage of Patient-Centered Care Over the 1-Year Study Period, Controlling for Baseline Patient Sex, Age, Education, Income, Physical Health Status, Mental Health Status, Obesity, Alcohol Abuse, and Smoking $(\mathrm{n}=494)$

\begin{tabular}{llrrr}
\hline Dependent Variable & Independent Variables & SE & $P$ & $\mathrm{R}^{2}$ \\
\hline $\begin{array}{l}\text { Total charges } \\
\text { (primary, specialty, and emergency care, }\end{array}$ & Female sex & Age & 0.1098 & .0115 \\
hospitalizations and diagnostic services) & Education & 0.2332 & $<.0001$ & 0.2142 \\
& Income & -0.0121 & .7803 & .7878 \\
& Physical health status & -0.0119 & -0.2327 & .0001 \\
& Mental health status & 0.0023 & .0564 \\
& Obesity & 0.0806 & .3317 \\
& Alcohol abuse & 0.0405 & .0701 \\
\hline
\end{tabular}

* Total Medical Charges with mean $7.22(\mathrm{SD}=1.59)$.

${ }^{\dagger}$ All independent variables are baseline measurements, except for the patient centered care which is averaged over one year of care. SE, standardized error. 
centered care during the year, controlling for age, education, income, physical health status, mental health status, obesity, alcohol abuse, and smoking. The results are displayed in Table 6 . Similar to the findings for the group as a whole, the average percentage of patient-centered care for female and male patients was positively associated with total annual medical charges $(P=.0255$ and $P=.0045$, respectively). Although the coefficients of determination for female and male patients were substantially different (0.1547 and 0.3118 , respectively), there was no significant difference for the average patient-centered care component in the 2 regressions $(P=.2607)$.

\section{Discussion}

Certain categories of health resource utilization (numbers of visits to specialty care clinics, hospitalizations, and laboratory and diagnostic tests) were found to be decreased for patients who had a greater average amount of patient-centered care during the time period.

In addition, we demonstrated a statistically significant association between patient-centered care and total charges for health service utilization during 1 year of care. This may be related to the decreased use of specialty care referrals (and the related charges) in those who received patient-centered care. In a previous study by Stewart and her associates ${ }^{14}$ using the Measure of Patient-Centered
Communication (MPCC) as well as the patients' perception of patient-centeredness, it was found that, although the MPCC scores were not significantly related to patient health status or health care utilization, patients who perceived that their visit had been patient-centered had significantly fewer diagnostic tests and referrals during the subsequent 2 months. A study by Epstein et $\mathrm{al}^{19}$ found that physicians with lower patient-centered care scores with 2 standardized patients (also using the MPCC) had greater total expenditures (testing, ambulatory, and hospital care) as assessed by their practice claims data during a 3-year period. These studies' findings provided preliminary evidence for a decreased utilization of medical resources by physicians whose practice style is characterized as patient-centered. Our study extended these findings by linking directly observed patient-centered care for actual study patients with decreased total medical charges over the course of the same year.

Despite sex differences previously noted in doctor-patient communication or utilization of medical services, both male and female patients displayed the same significant relationships between patient-centered care and health care utilization as that observed for the study group as a whole.

The pathway through which patient-centered care may lead to decreased utilization of health care resources remains to be fully understood. It has been demonstrated that a patient-centered ap-

Table 6. Standardized Estimates from Regression Equations in which Total Medical Charges* are Explained by the Average Percentage of Patient-Centered Care Over the 1-Year Study Period, for Female Compared to Male Patients Controlling for Baseline Patient Age, Education, Income, Physical Health Status, Mental Health Status, Obesity, Alcohol Abuse, and Smoking

\begin{tabular}{|c|c|c|c|c|c|c|}
\hline \multirow[b]{2}{*}{ Independent Variable ${ }^{\dagger}$} & \multicolumn{3}{|c|}{ Women $(\mathrm{n}=306)$} & \multicolumn{3}{|c|}{$\operatorname{Men}(\mathrm{n}=188)$} \\
\hline & SE & $P$ & $\mathrm{R}^{2}$ & SE & $P$ & $\mathrm{R}^{2}$ \\
\hline Age & 0.2339 & $<.0001$ & 0.1547 & 0.2530 & .0002 & 0.3118 \\
\hline Education & 0.0351 & .5370 & & -0.0672 & .3248 & \\
\hline Income & -0.0684 & .2412 & & 0.0781 & .2535 & \\
\hline Physical health status & -0.1647 & .0043 & & -0.3460 & $<.0001$ & \\
\hline Mental health status & 0.0178 & .7480 & & -0.0263 & .6822 & \\
\hline Obesity & 0.0764 & .1622 & & 0.0791 & .2223 & \\
\hline Alcohol abuse & 0.0029 & .9583 & & 0.0621 & .3356 & \\
\hline Smoking & 0.0838 & .1453 & & 0.0896 & .1707 & \\
\hline Patient-centered care & -0.1292 & .0255 & & -0.1889 & .0045 & \\
\hline
\end{tabular}

* Total medical charges are in log-transformed dollars, with mean 7.37 (SD, 1.51) for women and 6.97 (SD, 1.68) for men.

${ }^{\dagger}$ All independent variables are baseline measurements except for the patient centered care, which is averaged over 1 year of care. SE, standardized error. 
proach that includes increased patient participation during the visit reduces patients' anxiety and their perceived need for further investigations and referrals. ${ }^{14}$ Furthermore, when patients feel that their physician has an understanding of their illness and how it is affecting their lives, they may have greater trust in the physician, ${ }^{21}$ resulting in decreased requests for further testing and specialist consultations. Physician factors may also contribute to the process by which patient-centered interactions influence medical charges. In interactions characterized by patient-centered communication behaviors, such as exchanging information and managing uncertainty, the physician gains more knowledge about the patient, which may lead to less diagnostic uncertainty and decreased need to order additional diagnostic procedures. Alternatively, if a patient feels that they are not being understood, they may express their discontent with the interaction (verbally and nonverbally), potentially increasing the physician's anxiety and diagnostic uncertainty and leading to further investigations and referrals. ${ }^{22}$

It might be wondered whether the reduction in utilization of medical resources associated with patient-centered care was medically appropriate or inappropriate. There may be a margin of discretionary use of health care resources, such as diagnostic testing and use of specialist referrals, that is not necessary when both physician and patient are comfortable with the diagnosis and agreed on a treatment plan.

There are a number of limitations that may affect the generalization of our study's findings. The original study was conducted in the 1990s, and practice patterns may have shifted since that time. Physicians participating in this study were residents in their second and third year of training, and although professional practice patterns are developed during residency training, the practice styles of practicing community physicians may be different. In addition, the study patients may represent a population different from those receiving care in other settings. For example, self-reported health status measures for the study group were noted to be lower than national means.

This study, however, contributes to the literature on patient-centered communication and health care utilization by bringing a number of methodological strengths. The measures were based on a continuous year of care, not merely one patient visit; actual health care expenditures for the study patients were examined; the findings were based on direct observation of patient-centered visits (with a recognized interactional analysis system); and important patient variables such as choice of physician, type of visit, health status, health risk behaviors, and sociodemographic characteristics were controlled in the analyses.

\section{Conclusion}

An instrument adapted from the DOC has shown promise for use in research exploring patient-centered care. Patient-centered care using this instrument was to be significantly related to lower subsequent medical expenses without significantly adding to the length of the medical encounter. Although patient-centered care should not be promoted solely in the basis of cost considerations, it is important that its impact in health care costs be understood. Patient-centered care may result in greater knowledge of the patient, greater trust between physician and patient, and diminished need for additional specialty referrals, diagnostic testing, and use of hospital care. Further studies should examine whether patient-centered care is associated with a decrease in discretionary medical expenses versus appropriate expenses. Additional study is also needed to compare this instrument to other measures of patient-centered care (such as Dr. Moira Stewart's Measure of Patient-Centered Communication-MPCC) $)^{50}$ and to see if other measures of patient-centered care can replicate these findings in other settings. Nonetheless, our study provides compelling support for the use of a patient-centered approach in medical care and has obvious implications for a health care system being challenged to provide quality, personalized care in a cost-effective manner.

\section{References}

1. Stewart M. Towards a global definition of patientcentered care. BMJ 2001;233:444-5.

2. Mead N, Bower P. Patient-centredness: a conceptual framework and review of the empirical literature. Soc Sci Med 2000;51:1087-110.

3. Epstein RM, Franks P, Fiscella K, et al. Measuring patient-centered communication in patient-physician consultations: theoretical and practical issues. Soc Sci Med 2005;61:1516-28.

4. Epstein RM, Street RL Jr. Patient-centered communication in cancer care: promoting healing and reducing suffering. NIH Publ. No. 07-6225. Bethesda, MD: National Cancer Institute; 2007. 
5. Institute of Medicine. Crossing the quality chasm: a new health system for the 21 st century. Washington, DC: National Academy Press; 2001.

6. Mead N, Bower P. Measuring patient-centeredness: a comparison of three observation-based instruments. Patient Educ Couns 2000;39:71-80.

7. Toop L. Primary care: core values patient-centered primary care. BMJ 1998;316:1882-3.

8. Mead N, Bower P. Patient-centered consultations and outcomes in primary care: a review of the literature. Patient Educ Couns 2002;48:51-61.

9. Wolf DM, Lehman L, Quinlin R, Zullo T, Hoffman L. Effect of patient-centered care on patient satisfaction and quality of care. J Nurs Care Qual 2008;23: 316-21.

10. Kinnersley P, Stott N, Peter TJ, Harvey I. The patient-centredness of consultations and outcome in primary care. Br J Gen Pract 1999;49:711-6.

11. Winefield H, Murrell T, Clifford J, Farmer E. The search for reliable and valid measures of patientcentredness. Psychol Health 1996;11:811-24.

12. Mead N, Bower P, Hann M. The impact of general of general practitioners' patient centeredness on patients' post-consultation satisfaction and enablement. Soc Sci Med 2002;55:283-99.

13. Franks P, Jerant AF, Fiscella K, Shields CG, Tancredi DJ, Epstein RM. Studying physician effects on patient outcomes: physician interactional style and performance on quality of care indicators. Soc Sci Med 2006;62:422-32.

14. Stewart M, Brown JB, Donner A, et al. The impact of patient-centered care on outcomes. J Fam Pract 2000;49:796-804.

15. Radwin LE, Cabral HJ, Wilkes G. Relationships between patient-centered cancer nursing interventions and desired health outcomes in the context of the health care system. Res Nurs Health 2009;32:4-17.

16. Henbest RJ, Stewart M. Patient-centredness in the consultation 2: does it really make a difference. Fam Pract 1990;7:28-33.

17. Stewart MA. What is a successful doctor-patient interview? A study of interactions and outcomes. Soc Sci Med 1984;19:167-75.

18. Bertakis KD, Azari R, Callahan EJ, Helms LJ, Robbins JA. The impact of physician practice style on medical charges. J Fam Pract 1999;48:31-6.

19. Epstein RM, Franks P, Shields CG, Meldrum SC, et al. Patient-centered communication and diagnosis testing. Ann Fam Med 2005;3:415-21.

20. Bertakis KD, Azari R. Determinants and outcomes of patient-centered care. Patient Educ Couns $7 \mathrm{Au}-$ gust 2010 [Epub ahead of print].

21. Fiscella K, Meldrum S, Franks F, et al. Patient trust: is it related to patient-centered behavior of primary care physicians? Med Care 2004:42:1049-55.

22. Hjortdahl P, Borchgrevink CF. Continuity of care: influence of general practitioners' knowledge about their patients or use of resources in consultations. BMJ 1991;303:1181-4.

23. Bertakis KD, Callahan EJ, Helms LJ, Azari R, Robbins JA. The effect of patient health status on physician practice style. Fam Med 1993;25(8):530-5

24. Bertakis KD, Azari R. The influence of obesity, alcohol abuse, and smoking on utilization of health care services. Fam Med 2006;38:427-34.

25. Bertakis KD, Azari R. The impact of obesity on primary care visits. Obes Res 2005;13:1615-23.

26. Bertakis KD, Azari R. Determinants of physician discussion regarding tobacco and alcohol abuse. J Health Commun 2007;12:513-25.

27. Bertakis KD. The influence of gender on the doctorpatient relationship. Patient Educ Couns 2009;76: $356-60$

28. Hall JA, Roter DL. Patient gender and communication with physicians: results of a community-based study. Womens Health 1995;1:77-95.

29. Kaplan SH, Gandek B, Greenfield S, Rogers W, Ware JE. Patient and visit characteristics related to physicians' participatory decision-making style. Results from the Medical Outcomes Study. Med Care 1995;33:1176-87.

30. Bertakis KD, Azari R. Patient gender and physician practice style. J Womens Health (Larchmt) 2007;16: 859-68.

31. Bertakis KD, Frank P, Epstein RM. Patient-centered communication in primary care: physician and patient gender and gender concordance. J Womens Health 2009;18:539-45.

32. Bertakis KD, Azari R, Helms LJ, Callahan EJ, Robbins JA. Gender differences in the utilization of health care services. J Fam Pract 2000;49:147-52.

33. Bertakis KD, Callahan EJ, Helms LJ, Azari R, Robbins JA, Miller J. Physician practice styles and patient outcomes. Difference between family practice and general internal medicine. Med Care 1998;36:879-91

34. Callahan EJ, Bertakis KD. Development and validation of the Davis Observation Code (DOC). Fam Med 1991;23:19-24.

35. Callahan EJ, Bertakis KD, Azari R, Robbins JA, Helms LJ, Change DW. The influence of patient age on primary care resident physician-patient interaction. J Am Geriatr Soc 2000;48:30-5.

36. Callahan EJ, Bertakis KD, Azari R, Robbins JA, Helms LJ, Miller J. The influence of depression on physician-patient interaction in primary care. Fam Med 1996;28:346-51.

37. Bertakis KD, Azari R, Callahan EJ, Robbins JA, Helms LJ. Comparison of primary care resident physicians' practice styles during initial and return patient visits. J Gen Intern Med 1999;14:495-8.

38. Stange KC, Zyzanski SJ, Jaén CR, et al. Illuminating the "black box": a description of 4,454 patient visits to 138 family physicians. J Fam Pract 1998; 46:377-89 
39. Callahan EJ, Jaén CR, Crabtree BF, Zyzanski SJ, Goodwin MA. Stange KC. The impact of recent emotional distress and diagnosis of depression or anxiety on the physician-patient encounter in family practice. J Fam Pract 1998;46:410-8.

40. Barlow W, Lai M, Azen SP. A comparison of methods for calculating a stratified kappa. Stat Med 1991; 10:1465-72.

41. Stewart AL, Hays RD, Ware JE Jr. The MOS Shortform General Health Survey. Reliability and validity in a patient population. Med Care 1988;26:724-35.

42. Stewart AL, Greenfield S, Hay RD. Functional status and well-being of patients with chronic disease conditions. Results from the Medical Outcomes Study. JAMA 1989;262:907-13.

43. McHorney CA, Ware JE, Raczek AE. The MOS 36-item short-form health survey (SF-36): II. Psychometric and clinical tests validity in measuring physical and mental health constructs. Med Care 1993;31:247-63.

44. Ware JE, Kosinski M, Keller SD. SF-36 Physical and Mental Health Summary Scales: a user's manual. Boston: The Health Institute; 1994.

45. National Heart, Lung and Blood Institute. Clinical guidelines on the identification, evaluation, and treatment of overweight and obesity in adults: the evidence report. Bethesda, MD: National Institute of Health; 1998.

46. Selzer ML. The Michigan Alcoholism Screening Test: the quest for a new diagnostic instrument. Am J Psychiatry 1971;127:1653-8.

47. Pokorny AD, Miller BA, Kaplan HB. The brief MAST: a shortened version of the Michigan Alcoholism Screening Test. Am J Psychiatry 1972;129: 342-5.

48. Cherpitel CJ. Brief screening instruments for alcoholism. Alcohol Res Health 1997;21:348-51.

49. US Department of Health and Human Services. The health consequences of smoking: a report of the Surgeon General. Atlanta: US Department of Health and Human Services, Centers for Disease Control and Prevention, National Center for Chronic Disease Prevention and Health Promotion, Office on Smoking and Health; 2004

50. Brown J, Stewart M, Ryan BL. Assessing communication between patients and physicians: tThe Measure of Patient Centered Communication (MPCC) working paper series (2nd ed). London, Ontario, Canada: Thames Valley Family Practice Research Unit and Centre for Studies in Family Medicine; 2001. 